\title{
Competency-Based Approaches to Community Health: A Randomized Controlled Trial to Reduce Childhood Obesity among Latino Preschool-Aged Children
}

\author{
William J. Heerman, MD, MPH,' Leah Teeters, PhD,', Evan C. Sommer, BS, BA, \\ Laura E. Burgess, RD,' Juan Escarfuller, MA, MDiv,' Chelsea Van Wyk, MPH, \\ Shari L. Barkin, MD, MSHS, Ashley A. Duhon, BS, ${ }^{3}$ Jesse Cole, BSc, \\ Lauren R. Samuels, PhD, ${ }^{5}$ and Marcy Singer-Gabella, PhD ${ }^{6}$
}

\section{Abstract}

Background: Health behavior change interventions that target childhood obesity in minority populations have led to inconsistent and short-lived results. The purpose of this study was to test a novel intervention that was personalized and family-based in a Latino population to reduce childhood obesity.

Methods: Competency-Based Approaches to Community Health $(\mathrm{COACH})$ was a randomized controlled trial. Latino parent-child pairs were recruited from community settings in Nashville, TN. Child eligibility criteria included age $3-5$ years and a BMI $\geq 50$ th percentile. The intervention included 15 weekly, 90-minute sessions followed by 3 months of twice-monthly health coaching calls. The control group was a twice-monthly school readiness curriculum for 3 months. Sessions were conducted by a health coach in local community centers, with groups of 8-11 parent-child pairs. The primary outcome was child BMI trajectory across 12 months, measured at four times. The intervention's effect was assessed by using a longitudinal, linear mixed-effects growth model, adjusting for child gender, baseline child and parent age, and baseline parent BMI and education.

Results: Of the 305 parent-child pairs assessed for eligibility, 117 were randomized (59 intervention, 58 control). Child BMI was available for $91.5 \%$ at 1 -year follow-up. Mean baseline child age was 4.2 [standard deviation (SD) $=0.8$ ] years, and $53.8 \%$ of children were female. Mean baseline child BMI was $18.1(\mathrm{SD}=2.6) \mathrm{kg} / \mathrm{m}^{2}$. After adjusting for covariates, the intervention's effect on linear child BMI growth was $-0.41 \mathrm{~kg} / \mathrm{m}^{2}$ per year $(95 \%$ confidence interval -0.82 to $0.01 ; p=0.05)$.

Conclusions: Over 1-year follow-up, the intervention resulted in slower linear BMI growth for Latino preschool-aged children from poverty.

Keywords: behavioral interventions; childhood obesity; Latino families; qualitative research

\section{Background}

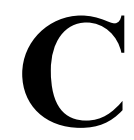

hildhood obesity rates among minority groups continue to be disproportionately higher than among white, non-Hispanic children. ${ }^{1}$ This health disparity is persistent, in part, because of inequity in social determinants of health. ${ }^{2,3}$ Families from minority communities face structural barriers to engaging in healthy behaviors that are necessary to support healthy childhood growth patterns, from unsafe neighborhoods to inadequate

\footnotetext{
'Department of Pediatrics, Vanderbilt University Medical Center, Nashville, TN.

${ }^{2}$ Department of Psychology and Neuroscience, University of Colorado Boulder, Boulder, CO.

${ }^{3}$ School of Medicine, Louisiana State University Health Sciences Center New Orleans, New Orleans, LA.

${ }^{4}$ Jacobs School of Medicine and Biomedical Sciences, SUNY at Buffalo, Buffalo, NY.

${ }^{5}$ Department of Biostatistics, Vanderbilt University Medical Center, Nashville, TN.

${ }^{6}$ Department of Teaching and Learning, Vanderbilt University, Nashville, TN.
} 
access to healthy foods. ${ }^{4,5}$ Health disparities in childhood obesity begin in early childhood, which confers long-term risk of cardiovascular disease, cancer, and diabetes to these children already at risk. ${ }^{6}$ These challenges are particularly salient for Latino children, where the prevalence of obesity among preschool-aged children aged $2-4$ years is $17.3 \%{ }^{7}$

The medical community has sought to address these disparities by developing interventions that are designed to reduce childhood obesity among minority children, which have consistently led to small and unsustained improvements in child weight. ${ }^{8-10}$ In particular, two recently conducted randomized trials among predominantly Latino families did not achieve their primary outcome of obesity prevention among preschool-aged children. ${ }^{11,12}$ These findings are consistent with a previous systematic review that identified only a few successful interventions among Latino children, all of which were among older children. ${ }^{13}$ One reason that childhood obesity interventions for children from low-income and minority communities may fail is that intervention content may not account for the wide variability of cultural, social, and psychological factors that contribute to both obesity and its determinative health behaviors. ${ }^{14,15}$ Although multi-level interventions that address the community, family, and individual level have drawn much attention of late, it is often difficult to achieve the meaningful changes in the social environment necessary to affect improvements in child weight.

Another alternative to addressing the social determinants of health that contribute to childhood obesity is by developing interventions to support personal agencydefined by Bandura as a person bringing "their influence to bear on their own functioning and on environmental events." 16 Strategies developed in the learning sciences suggest that improving agency requires a personalized instructional approach that allows for tailoring of intervention content to reduce the variability in outcomes. ${ }^{14,17}$ This paradigm is consistent with the notion of personalized health, which recognizes that a one-sized-fits-all intervention is unlikely to be most effective for all participants.

The purpose of this study is to test the effectiveness of a novel intervention, Competency-Based Approaches to Community Health (COACH), on changes in child BMI over 1 year of follow-up. Using the paradigm of personalized medicine, we aim at preventing and treating childhood obesity through a personalized family-based intervention in local parks and recreation centers by facilitating agency for health behavior change among minority parent-child pairs.

\section{Methods}

The COACH Trial was a parallel-group, individually randomized controlled trial (RCT) designed to prevent/ treat childhood obesity by delivering a personalized, family-centered intervention to parent-child pairs. The full methods and study design have been previously reported. ${ }^{14,18}$ The Vanderbilt Medical Center Institutional
Review Board approved the study protocol. Written informed consent was obtained by bilingual data collectors in Spanish by using an enhanced, low-literacy approach. ${ }^{19,20}$ The study was registered on clinicaltrials.gov (NCT03141151) before participants were enrolled.

\section{Setting and Participants}

Parent-child pairs were recruited from physicians' offices and community settings in Nashville, TN. Enrollment occurred between May 2017 and August 2017. The final 12-month follow-up was conducted between May 2018 and August 2018. Child eligibility criteria included age 3-5 years, Spanish speaking, and a BMI $\geq 50$ th percentile based on US Centers for Disease Control and Prevention standardized growth curves. ${ }^{21}$ Participants were excluded if a medical condition precluded routine physical activity or if parents lived outside of specified zip code regions that were contiguous to intervention sites at local community centers. Race and ethnicity information was collected because obesity disproportionately affects children from underserved minorities. ${ }^{22}$ Race and ethnicity for both parent and child were assessed by parent report. To be eligible, parents had to self-identify as Hispanic/Latino.

\section{Randomization}

Participants were randomized by using a computergenerated schedule that included randomly permuted block sizes from 2 to 6 . Assignment was implemented through an electronic interface, concealing group assignment before enrollment. Only study staff not involved in data collection implemented randomization. Group assignment could not be changed.

\section{Intervention Description}

The intervention consisted of two phases: an intensive in-person phase and a maintenance phone-call phase. The intensive phase consisted of weekly sessions for 15 weeks, and each session lasted 90 minutes. The intention of the curriculum was to build parent and child agency for health behaviors through a personalized approach. The content of modules included didactic and skills-building sessions on healthy diet, physical activity, sleep, engaged parenting, and media use. Each session was conducted in a local park and recreation community center, with a group of 8-11 participants. When participants could not make a session in person, the health coach would call the participant and complete a make-up session by phone. These sessions typically lasted 20-30 minutes. The curricular components that facilitated a personalized approach included (1) individual assessment of competency in seven health behaviors, (2) the development of individualized learning plans, and (3) giving participants the choice about which content areas to spend extra time on during sessions. Personalization occurred each week when the group decided on an area on which to focus additional time and through four "intercessions" throughout the 15 weeks where participants received individualized coaching on topic areas they 
selected. Each session was designed around key components of the behavior change theory, with a focus on goal setting, self-monitoring, and problem-solving. Children participated in a concurrent session designed to mirror the adult intervention. These sessions included: (1) an interactive didactic component, (2) a hands-on connected activity, (3) stretching and physical activity, and (4) a review. Children then joined the parent session for shared interaction around material learned in the session and a shared meal. As a part of each session, the parents received written materials to reinforce key messages. ${ }^{23}$

The maintenance phase consisted of twice-monthly coaching calls for 3 months. Health coaches used motivational interviewing to set personalized family health goals, gauge progress on previous goals, and problem-solve with participants. ${ }^{24}$ Health coaches were trained and certified research assistants, who were natively bilingual.

The control group consisted of sessions twice a month for 3 months. The content was developed by the Nashville Public Library and focused on school readiness with the following topics: (1) Getting Ready to Read, (2) Home is a Learning Zone, (3) Fun with Play, (4) Words and Letters in the World Around Us, (5) Work that Body, Feed that Mind, and (6) Parent Advocacy in School. ${ }^{25}$ There was also a field trip to the local library.

All sessions (both intervention and control) were conducted in Spanish by the same natively bilingual health coach.

\section{Blinding}

Data collectors were blinded to individual participant study condition. All study staff, including the primary investigator and statisticians, were blinded to postbaseline data aggregated by the group until all study data had been collected and cleaned.

\section{Outcomes}

The prespecified primary outcome was child BMI trajectory across 12 months, modeled by using linear and quadratic terms. ${ }^{11}$ BMI was calculated as weight in kilograms divided by height in meters squared. The protocol identified seven prespecified secondary outcomes: (1) child diet, (2) child physical activity, (3) parent BMI, (4) parent diet practices, (5) parent physical activity, (6) parent selfefficacy for child health behaviors, and (7) parenting practices that encourage/discourage child physical activity. Child BMI-Z score was added as a post hoc secondary outcome.

Data were collected at baseline and 4, 7, and 12 months by trained and certified bilingual data collectors in participant homes or local community centers. Data collected included parent and child height using stadiometers (without shoes, to nearest $0.1 \mathrm{~cm}$ ) and weight using research-grade and calibrated scales (to nearest $0.1 \mathrm{~kg}$ ). Survey data were collected in Spanish via guided administration. Survey domains included demographic, behavioral, and psychosocial domains. Acculturation was measured by using the Brief Acculturation Scale for Hispanics (BASH) ${ }^{26}$ BASH scores range from 4 to 20 , with low scores indicating low acculturation. Child diet was measured by nine single survey items used in the Feeding Infants and Toddlers Study ${ }^{27}$ (soda, juice, sugary drinks, fruits, vegetables, sweets, snacks, other dairy, and water), with higher values representing higher frequency of consumption per day. Child physical activity was measured by parent self-report, by asking in a typical week how many days the child was physically active for at least 60 minutes/day. Diet practices were measured by using a summed score of a 4-item questionnaire of eating behaviors, including overeating, unplanned eating, making poor food choices, and emotional eating. ${ }^{28}$

Parent physical activity was measured by using the Behavioral Risk Factor Surveillance System (BRFSS) module for physical activity, and it combines parent moderate-tovigorous physical activity (MVPA) and walking time to account for total active time. ${ }^{29}$ Parenting self-efficacy for child health behaviors was measured by using a 16-item scale, with four sub-scales: avoiding sugary beverages, avoiding fruit juice, supporting fruits and vegetables intake, and supporting physical activity. ${ }^{30}$ Parenting practices around child physical activity were measured by the Preschooler Physical Activity Parenting Practices (PPAPP) scale, which is divided into two sub-scales measuring practices that encourage (15 items) and discourage (14 items) child physical activity. ${ }^{31}$

Process measures included fidelity to implementation, measured by using a standardized interventionist feedback form that captured qualitative assessment of fidelity to the intervention protocol from both the interventionist and trained study staff, and dose delivered, measured by attendance at both intensive in-person and maintenance coaching phone-call sessions.

\section{Adverse Event Reporting}

Adverse events were identified throughout the study period by a structured questionnaire at all data collection time points. Participants were also encouraged to contact the study team if an event occurred between measurement time points.

\section{Sample Size}

A power analysis was conducted with a two-tailed $\alpha=0.05$ and $80 \%$ power to detect a standardized effect size of 0.4. Results suggested that 100 pairs were required. The effect size of 0.4 was selected based on data from previous clinical trials for childhood obesity among Latino participants. $^{11}$

\section{Statistical Methods}

Baseline characteristics were reported as mean [standard deviation (SD)] or number (\%) for categorical variables. The analysis used an intention-to-treat approach designed to test the difference in the BMI growth trajectory between children in the intervention and control groups. As specified a priori, BMI trajectory was modeled by using a linear 
and a quadratic term, given the nonlinear nature of early child growth. The original analysis used a longitudinal mixed-effects regression model with two levels (time nested within child), three random effects (intercept, linear, and quadratic), and an unstructured variance-covariance matrix. ${ }^{32}$ BMI data were assumed to be missing at random, and the model used a maximum likelihood procedure to handle missing outcome data ( $\sim 10 \%$ missing BMI data across all time points). ${ }^{33}$ Measurement time varied individually and was measured continuously as years since baseline data collection. Child gender was a covariate for the intercept. Child age and intervention condition were covariates for the intercept, linear, and quadratic terms. Intervention effectiveness was evaluated by a likelihood ratio test to determine whether the linear and quadratic intervention effects were jointly equal to zero $(\mathrm{df}=2 ; 0.05$ level $)$.

However, because the linear term alone might be sufficient to adequately capture child BMI trajectory in this relatively short one-year timeframe, the original quadratic model fit was compared with an otherwise identical nested linear model by using a likelihood ratio test and the Akaike Information Criterion (AIC) and Bayesian Information Criterion (BIC). Baseline parent education, BMI, and age were then added to the final linear model as covariates for the intercept and linear terms. To assess the potential for post-randomization cluster effects due to participants meeting in small, consistent subgroups throughout the trial, we fit a model with an additional level for children clustered within the intervention subgroup. ${ }^{34}$ This model demonstrated a near-zero variance and intracluster correlation coefficient at the subgroup level and did not affect parameter estimates or confidence intervals (CIs). Therefore, results from the more parsimonious model without a level for subgroup are presented.

Secondary and post hoc outcomes were analyzed by using ordinary least-squares regression when residual diagnostics did not confirm violation of distributional assumptions. The child diet items were analyzed as noninteger count variables by using Poisson regression with robust standard errors to control for mild assumption violation, ${ }^{35}$ and goodness-of-fit was evaluated by using tests of both the deviance and Pearson statistics. ${ }^{36}$ The child and parent physical activity outcomes were analyzed by using negative binomial regression because their distributions were severely over-dispersed (variance vastly exceeded the mean). ${ }^{37}$ Models were prespecified and adjusted for covariates hypothesized to be associated with each outcome. All secondary models included the baseline outcome as a covariate. The child outcome models (child diet and child physical activity) also adjusted for baseline child age, child gender, and parent education; whereas the parent outcome models (BMI, diet practices, physical activity, selfefficacy, and parenting practices related to child physical activity) adjusted for baseline parent age and education.

In post hoc analyses, we used ordinary least-squares multivariable regression to test the relationship between attendance at sessions (dose) and child BMI-Z at the 7- and 12-month follow-up. A separate model was conducted for each dose modality (i.e., the number of intensive phase inperson contacts delivered, and the number of maintenance phone calls completed). A third model tested the interaction of the two dose modalities by including each of the main effects and their interaction. To evaluate for a potential nonlinear relationship between dose and BMI-Z, we repeated the linear regression by using two different approaches: (1) restricted cubic splines and (2) a categorical dose variable [0-5 sessions (ref) vs. 6-10 sessions vs. 11-15 sessions]. Because interpretation of diagnostic plots and the model with restricted cubic splines provided no evidence for nonlinearity, we present the model treating dose categorically for ease of interpretation. The control group was included and had zero dose for all models in the dose analysis. All models adjusted for baseline child age and gender.

Statistical analyses were conducted by using Stata version 15.1 (StataCorp). Statistical significance was defined by using a two-sided test with $\alpha=0.05$.

\section{Results}

Of the 305 parent-child pairs assessed for eligibility, 117 were randomized, with 59 assigned to the intervention group and 58 to the control group. The 12-month retention rate was $90 \%$ for the intervention and $93 \%$ for the control (Fig. 1). At baseline, child mean age was $4.2(\mathrm{SD}=0.8), 53.8 \%$ were female, and mean child BMI was $18.1(\mathrm{SD}=2.6) \mathrm{kg} / \mathrm{m}^{2}$. Almost all (99.1\%) index parents were women, $48.7 \%$ did not graduate high school or obtain a GED, and the household income among those who reported a value was $<\$ 20,000$ for $53.8 \%(n=35 / 65)$. At baseline, parent acculturation was very low, with an average BASH score of 5.0 (SD 2.0). Table 1 shows baseline data by intervention group.

\section{Primary Outcome}

The mean child BMI at 12 months was $18.5(\mathrm{SD}=2.7)$ in the intervention group and $18.7(\mathrm{SD}=3.7)$ in the control group. The final linear mixed-effects model with all covariates showed an adjusted linear intervention effect of $-0.41 \mathrm{~kg} / \mathrm{m}^{2}$ per year [(95\% CI -0.82 to 0.01$\left.) ; p=0.05\right]$. Model-estimated child BMI trajectories are shown in Figure 2. Adjusted BMI difference estimates at each follow-up time point are shown in Table 2.

\section{Secondary Outcomes}

Analysis of secondary outcomes at the 4-month time point is shown in Tables 3 and 4, and secondary outcomes at 7 and 12 months are shown in Appendix Tables A1 and A2. At 4 months (immediately after the intensive phase of the intervention), there were statistically significant, beneficial intervention effects on parent-combined minutes spent in MVPA and walking [Incidence Rate Ratio $($ IRR $)=1.99 ;(95 \%$ CI 1.16-3.42); $p=0.01]$, all four domains of parent self-efficacy for child health behaviors [sugar: $\mathrm{B}=2.24 ;(95 \% \mathrm{CI} 0.70-3.77) ; p=0.005$, juice: $\mathrm{B}=1.59$; (95\% CI $0.05-3.13) ; p=0.04$, physical activity: $\mathrm{B}=2.00 ;(95 \%$ CI $0.74-3.25) ; p=0.002$, fruits/vegetables: 


\section{Enrollment}



Figure 1. Consolidated Standards of Reporting Trials (CONSORT) diagram.

$\mathrm{B}=1.71 ;(95 \%$ CI $0.47-2.95) ; p=0.01]$, two domains in the PPAPP scale [engagement: $\mathrm{B}=6.14$; $(95 \%$ CI $1.61-$ $10.68) ; p=0.009$, psychological control: $\mathrm{B}=-1.24 ;(95 \%$ CI -2.35 to -0.13$) ; p=0.03$, and two parent-reported child diet items [vegetables: IRR $=1.91$; $(95 \%$ CI $1.22-2.99)$; $p=0.005$, and snacks: IRR $=0.62 ;(95 \%$ CI $0.42-0.94)$; $p=0.02]$. These differences were not sustained at other follow-up time points.
There were no statistically significant differences in the other child diet items, child number of days physically active, parent BMI, parent dieting practices, or parent number of days physically active.

\section{Adherence to the Study Protocol}

The mean number of intensive phase sessions completed was 11.0 of $15 \quad(\mathrm{SD}=5.5$; including phone make-up 
Table I. Characteristics of the Participants at Baseline

Child characteristics

\begin{tabular}{|c|c|c|c|}
\hline Gender, $N$ female (\% female) & $63(53.8)$ & $32(54.2)$ & $31(53.4)$ \\
\hline Age at anthropometry collection (years) & $4.2(0.8)$ & $4.3(0.8)$ & $4.2(0.8)$ \\
\hline \multicolumn{4}{|l|}{ Anthropometry } \\
\hline BMI $\left(\mathrm{kg} / \mathrm{m}^{2}\right)$ & I8.I (2.6) & $18.1(2.2)$ & $18.1(3.0)$ \\
\hline BMI percentile & $85.7(13.6)$ & $85.6(15.3)$ & 85.7 (II.8) \\
\hline BMI-Z score & $1.5(1.0)$ & $1.4(0.9)$ & $1.5(1.1)$ \\
\hline \multicolumn{4}{|l|}{ BMI weight status, $N(\%)$} \\
\hline Normal (5th to less than the 85 th percentile) & $47(40.2)$ & $20(33.9)$ & $27(46.6)$ \\
\hline Overweight (85th to less than the 95 th percentile) & $26(22.2)$ & $14(23.7)$ & $12(20.7)$ \\
\hline Obese (equal to or greater than the 95 th percentile) & $44(37.6)$ & $25(42.4)$ & $19(32.8)$ \\
\hline \multicolumn{4}{|l|}{ Race/ethnicity, N (\%) } \\
\hline Hispanic & $117(100.0)$ & $59(100.0)$ & $58(100.0)$ \\
\hline \multicolumn{4}{|l|}{ Parent characteristics } \\
\hline Gender, $N$ female (\% female) & $116(99.1)$ & $58(98.3)$ & $58(100.0)$ \\
\hline Age at anthropometry collection (years) & $32.5(6.0)$ & $31.7(5.4)$ & $33.4(6.4)$ \\
\hline \multicolumn{4}{|l|}{ Anthropometry } \\
\hline BMI $\left(\mathrm{kg} / \mathrm{m}^{2}\right)$ & $31.0(6.2)$ & $30.2(5.8)$ & $31.9(6.5)$ \\
\hline \multicolumn{4}{|l|}{ BMI weight status, $N(\%)$} \\
\hline Normal $\left(\mathrm{BMl}<25 \mathrm{~kg} / \mathrm{m}^{2}\right)$ & $21(17.9)$ & $12(20.3)$ & $9(15.5)$ \\
\hline Overweight (BMI $\geq 25$ and $<30 \mathrm{~kg} / \mathrm{m}^{2}$ ) & $38(32.5)$ & $22(37.3)$ & $16(27.6)$ \\
\hline Obesity (BMI $\geq 30 \mathrm{~kg} / \mathrm{m}^{2}$ ) & $58(49.6)$ & $25(42.4)$ & $33(56.9)$ \\
\hline \multicolumn{4}{|l|}{ Race/ethnicity, N (\%) } \\
\hline Hispanic & $117(100.0)$ & $59(100.0)$ & $58(100.0)$ \\
\hline Brief Acculturation Scale for Hispanics & $5.0(2.0)$ & $4.8(1.6)$ & $5.2(2.4)$ \\
\hline \multicolumn{4}{|l|}{ Employment status, $N(\%)$} \\
\hline Working full time & $32(27.4)$ & $16(27.1)$ & $16(27.6)$ \\
\hline Unemployed & $8(6.8)$ & $6(10.2)$ & $2(3.4)$ \\
\hline Homemaker/stay at home parent & $76(65.0)$ & 37 (62.7) & $39(67.2)$ \\
\hline Full-time student & I $(0.9)$ & $0(0.0)$ & $\mathrm{I}(\mathrm{I} .7)$ \\
\hline \multicolumn{4}{|l|}{ Marital status, $\mathrm{N}(\%)$} \\
\hline Married or living as married & $107(91.5)$ & $54(91.5)$ & $53(91.4)$ \\
\hline Single & $10(8.5)$ & $5(8.5)$ & $5(8.6)$ \\
\hline \multicolumn{4}{|l|}{ Household income, $N(\%)$} \\
\hline Less than $\$ 10,000$ & $4(3.4)$ & $2(3.4)$ & $2(3.4)$ \\
\hline$\$ 10,000-\$ 19,999$ & $31(26.5)$ & $17(28.8)$ & $14(24.1)$ \\
\hline$\$ 20,000-\$ 34,999$ & $23(19.7)$ & $10(16.9)$ & $13(22.4)$ \\
\hline$\$ 35,000-\$ 49,999$ & $6(5.1)$ & $2(3.4)$ & $4(6.9)$ \\
\hline$\$ 50,000-\$ 74,999$ & I (0.9) & $0(0)$ & $\mathrm{I}(\mathrm{I} .7)$ \\
\hline Do not know or no answer & $52(44.4)$ & $28(47.5)$ & $24(4 I .4)$ \\
\hline
\end{tabular}




\section{Table I. Characteristics of the Participants at Baseline continued}

\begin{tabular}{l|c|c|c}
\multirow{2}{*}{ Parent education, $N(\%)$} & \multicolumn{2}{|c}{ Means or frequencies } \\
\cline { 2 - 4 } & Total $(\mathbf{N}=$ I I 7) & Intervention (N=59) & \\
\hline Some high school or less & & $27(45.8)$ & $30(51.7)$ \\
\hline High school graduate (or GED) or more & $60(51.3)$ & $32(54.2)$ & $28(48.3)$ \\
\hline
\end{tabular}

Values are mean (SD), unless otherwise noted. BMI was calculated as weight in kilograms dived by the square of height in meters.

SD, standard deviation.

sessions), the mean number of intensive phase in-person sessions was $6.5(\mathrm{SD}=4.9)$, and the mean number of maintenance phase phone call sessions was 3.6 out of 6 $(\mathrm{SD}=2.6)$. Full distribution of the dose delivered to participants is shown in Appendix Tables A3 and A4. No cross-over occurred between conditions. Fidelity to the intervention was assessed by using a qualitative approach and was consistently high.

\section{Dose Analysis}

Participants with higher intensive in-person attendance had lower child BMI-Z scores at 7 months $[\mathrm{B}=-0.017$; (95\% CI -0.032 to -0.003$) ; p=0.02]$ but the relationship was not statistically significant at 12 months. In addition, participants with higher maintenance phone-call completion had lower child BMI-Z at 7 months $[\mathrm{B}=-0.036 ;(95 \%$ $\mathrm{CI}-0.063$ to -0.009$) ; p=0.01]$ but the relationship was not statistically significant at 12 months. The interaction between attendance at intensive in-person sessions and completion of maintenance phone-call coaching sessions was not statistically significant at 7 or 12 months. Evalu-

Model-Estimated Overall Intervention and Control Group BMI Trajectories Over 1 Year 20

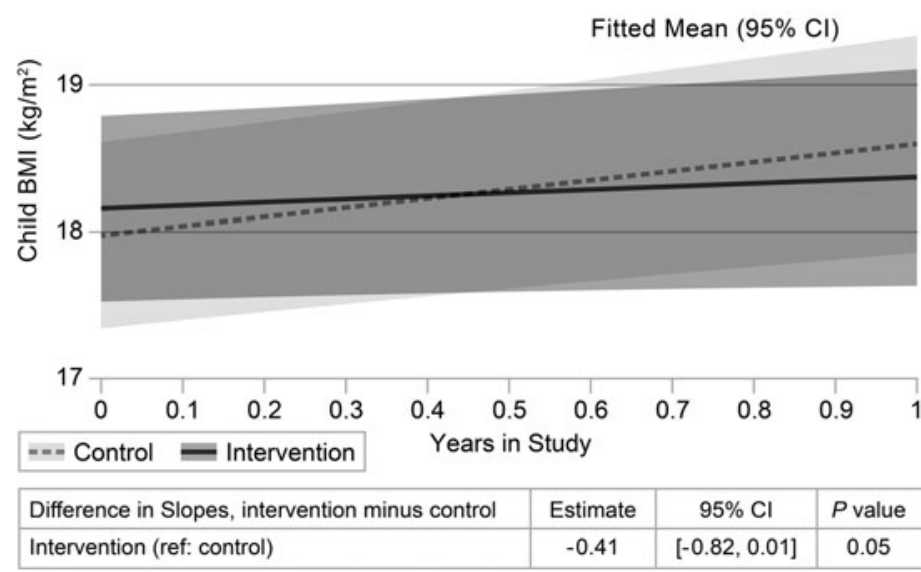

Figure 2. Model-estimated overall intervention and control group BMI trajectories over 1 year. ating for a potential nonlinear relationship between dose and outcome, compared with participants who attended 0 5 in-person sessions, participants who attended 6-10 inperson sessions had significantly lower child BMI-Z scores at 7 months $[\mathrm{B}=-0.22 ;(95 \% \quad \mathrm{CI}=-0.41$ to -0.02$)$; $p=0.028]$, and participants who attended 11-15 in-person sessions had marginally significantly lower child BMI-Z scores at 7 months $[\mathrm{B}=-0.20 ;(95 \%-0.41$ to 0.02$)$; $p=0.08]$. The 7-month BMI-Z of participants who attended 6-10 in-person sessions was not significantly different from those who attended 11-15 in-person sessions $[\mathrm{B}=-0.02 ;(95 \% \mathrm{CI}=-0.29$ to 0.24$) ; p=0.9]$. The results of the dose analysis at 7 and 12 months are shown in Appendix Tables A3 and A4.

\section{Adverse Events}

There were no adverse events related to the study.

\section{Discussion}

This personalized, family-centered behavioral intervention resulted in slower linear BMI growth $\left[-0.41 \mathrm{~kg} / \mathrm{m}^{2}\right.$ per year $(95 \% \mathrm{CI}=-0.82$ to 0.01$)]$ over 1 year in Latino preschool-aged children from low-income families. Compared with parents in the control group, intervention group parents demonstrated improvements in secondary behavioral outcomes such as self-efficacy at 4-month follow-up (immediately after the intensive phase of the intervention). The intervention demonstrated high fidelity to intervention content, with low differential dropout between groups. Exploratory analyses indicated that children who attended higher numbers of intervention sessions had lower BMI-Z at the 7-month follow-up, though the dose relationship was nonlinear; whereas children who attended at least 6 in-person sessions were just as likely to have lower BMI-Z at 7 months of follow-up compared with children who attended at least 11 sessions. These findings suggest that the personalized approach implemented in the intervention led to improvements in child BMI in preschool-aged children over 1 year of follow-up.

The previous decade has seen hundreds of behavioral RCTs targeted at childhood obesity prevention and treatment. ${ }^{38,39}$ Large systematic reviews of these trials have 
Table 2. Child BMI at Each Time Point

\begin{tabular}{|c|c|c|c|c|c|c|c|c|c|}
\hline \multirow[b]{2}{*}{ Time points } & \multicolumn{3}{|c|}{ Intervention } & \multicolumn{3}{|c|}{ Control } & \multirow{2}{*}{$\begin{array}{l}\text { Adjusted BMI } \\
\text { difference }^{\mathrm{a}}\end{array}$} & \multirow[b]{2}{*}{$95 \% \mathrm{Cl}$} & \multirow[b]{2}{*}{$p$} \\
\hline & $n$ & Mean & SD & $n$ & Mean & SD & & & \\
\hline Baseline & 59 & 18.1 & 2.2 & 58 & 18.1 & 3.0 & 0.18 & -0.72 to 1.08 & 0.70 \\
\hline 4 Months & 56 & 18.1 & 2.5 & 56 & 18.2 & 3.4 & 0.05 & -0.89 to 0.98 & 0.92 \\
\hline 7 Months & 52 & 18.0 & 2.5 & 55 & 18.4 & 3.3 & -0.02 & -0.98 to 0.94 & 0.96 \\
\hline 12 Months & 52 & 18.5 & 2.7 & 54 & 18.7 & 3.7 & -0.23 & -1.28 to 0.83 & 0.67 \\
\hline
\end{tabular}

Data are means (SD) unless otherwise indicated.

${ }^{a} B M I$ differences over time are estimates from the longitudinal mixed-effects regression model.

$95 \% \mathrm{Cl}, 95 \%$ confidence interval.

identified variable effectiveness, especially among lowincome minority populations. ${ }^{40-45}$ For example, one systematic review identified small-to-medium effect sizes (Cohen's $f=0.26$ ) among four obesity trials conducted in older children. ${ }^{13}$ In addition, the majority of successful obesity trials to date have focused on short-term improvements in child BMI. Dynamic barriers to health behavior change in low-income families may be one of the many reasons that it is so difficult to sustain changes in BMI over longer follow-up periods. The current trial advances the field by demonstrating a successful intervention among Latino preschool-aged children over 1 year of follow-up. The reasons underpinning the observed changes in child linear BMI growth cannot be fully elicited, due to inadequate power to conduct mediation analyses. However, we hypothesize that the success of the intervention at 1 year was due to the nature of the personalized curriculum, which focused on tailoring content to families' areas of greatest need while teaching them strategies to leverage strengths and navigate changing community-, family-, and individual-level barriers.
One of the main contributions of this intervention is to the theory and methodology of implementing a personalized health behavior change intervention in the setting of childhood obesity. ${ }^{14}$ Individual tailoring has long been a standard in health interventions. However, we conceptualize the $\mathrm{COACH}$ intervention as a "personalized intervention" as it combines the notion of tailoring intervention content while being delivered in a group setting. In addition to typical self-directed goal setting, we implemented several curricular components that facilitated the personalized approach, including an individualized assessment of health competency, tailoring of content each week to participants' preferences, intercessions, and coaching calls. Although some of these were designed to give one-on-one individualized content (e.g., intercessions and coaching calls), we suggest that the group component enhanced the personalized content by providing a mechanism for shared problem solving in the social-ecological context.

One of the challenges to conducting obesity interventions is that the current literature is not clear about the optimal timing of interventions or the optimal setting for

\section{Table 3. Secondary Outcomes at 4 Months: Child Diet Items}

\begin{tabular}{|c|c|c|c|c|c|c|c|c|c|}
\hline \multirow[b]{2}{*}{ Child diet item } & \multicolumn{3}{|c|}{ Intervention $(n=59)$} & \multicolumn{3}{|c|}{ Control $(n=58)$} & \multirow{2}{*}{$\begin{array}{l}\text { Adjusted incidence } \\
\text { rate ratio }\end{array}$} & \multirow[b]{2}{*}{$95 \% \mathrm{Cl}$} & \multirow[b]{2}{*}{$p$} \\
\hline & No. with data (\%) & Mean & SD & No. with data (\%) & Mean & SD & & & \\
\hline Soda & 56 & 0.17 & 0.27 & 55 & 0.19 & 0.31 & 0.96 & $0.5 \mathrm{I}-\mathrm{I} .79$ & 0.9 \\
\hline Juice & 56 & 0.46 & 0.64 & 55 & 0.28 & 0.55 & 1.69 & $0.94-3.04$ & 0.08 \\
\hline Sweetened drinks & 56 & 0.35 & 0.65 & 55 & 0.51 & 0.62 & 0.72 & $0.42-1.24$ & 0.2 \\
\hline Fruit & 56 & 1.85 & 1.40 & 54 & 1.49 & 0.82 & 1.19 & $0.95-1.49$ & 0.1 \\
\hline Vegetables & 56 & 0.32 & 0.44 & 55 & 0.19 & 0.22 & 1.91 & $1.22-2.99$ & 0.005 \\
\hline Sweets & 56 & 0.37 & 0.52 & 55 & 0.51 & 0.48 & 0.71 & $0.43-1.16$ & 0.2 \\
\hline Snacks & 56 & 0.15 & 0.20 & 55 & 0.24 & 0.19 & 0.62 & $0.42-0.94$ & 0.02 \\
\hline Other dairy & 56 & 0.91 & 1.08 & 55 & 0.68 & 0.67 & 1.15 & $0.79-1.67$ & 0.5 \\
\hline Water & 56 & 2.89 & 1.38 & 55 & 2.72 & 1.41 & 1.06 & $0.89-1.27$ & 0.5 \\
\hline
\end{tabular}

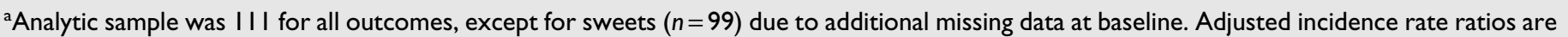
Poisson regression model estimates adjusting for baseline value of the outcome variable, child gender, child age at baseline, and parent education. 
Table 4. Secondary Outcomes at 4 Months: Child and Parent Other Health Outcomes

\begin{tabular}{|c|c|c|c|c|c|c|c|c|c|}
\hline \multirow[b]{2}{*}{ Secondary outcome } & \multicolumn{3}{|c|}{ Intervention $(n=59)$} & \multicolumn{3}{|c|}{ Control $(n=58)$} & \multirow{2}{*}{$\begin{array}{c}\text { Adjusted } \\
\text { difference } \\
\text { or incidence } \\
\text { rate ratio }\end{array}$} & \multirow[b]{2}{*}{$95 \% \mathrm{Cl}$} & \multirow[b]{2}{*}{$p$} \\
\hline & $\begin{array}{l}\text { No. with } \\
\text { data (\%) }\end{array}$ & Mean & SD & $\begin{array}{l}\text { No. with } \\
\text { data (\%) }\end{array}$ & Mean & SD & & & \\
\hline Child active days per week & 55 & 2.00 & 2.60 & 55 & 1.62 & 2.63 & 1.02 & 0.54 to 1.90 & $>0.9$ \\
\hline Parent BMI $\left(\mathrm{kg} / \mathrm{m}^{2}\right)$ & 50 & 30.44 & 5.86 & 49 & 31.57 & 6.72 & -0.02 & -0.36 to 0.33 & 0.9 \\
\hline Parent diet practices & 55 & 5.04 & 4.09 & 54 & 5.22 & 4.02 & -0.80 & -2.13 to 0.53 & 0.2 \\
\hline Parent active days per week & 56 & 1.73 & 2.12 & 55 & 1.05 & 1.78 & 1.62 & 0.94 to 2.79 & 0.08 \\
\hline Parent MVPA per week (minutes) & 53 & 114.68 & 160.09 & 54 & 59.61 & 106.24 & 1.82 & 0.92 to 3.63 & 0.09 \\
\hline Parent MVPA+walking per week (minutes) & 52 & 187.92 & 206.01 & 54 & 109.98 & 134.78 & 1.99 & 1.16 to 3.42 & 0.01 \\
\hline \multicolumn{10}{|l|}{ Parent self-efficacy for child health behaviors } \\
\hline Avoid sugary drinks & 56 & 11.96 & 4.46 & 55 & 10.11 & 3.79 & 2.24 & 0.70 to 3.77 & 0.005 \\
\hline Avoid fruit juice & 56 & 11.41 & 4.70 & 54 & 9.59 & 3.49 & 1.59 & 0.05 to 3.13 & 0.04 \\
\hline Encourage physical activity & 56 & 11.45 & 4.04 & 55 & 9.67 & 3.06 & 2.00 & 0.74 to 3.25 & 0.002 \\
\hline Encourage fruits and vegetables & 55 & 11.53 & 4.01 & 55 & 9.69 & 2.76 & 1.71 & 0.47 to 2.95 & 0.007 \\
\hline \multicolumn{10}{|l|}{ PPAPP scale encourage } \\
\hline Engagement & 56 & 53.79 & 12.66 & 54 & 49.52 & 13.06 & 6.14 & 1.61 to 10.68 & 0.009 \\
\hline Lack money for sports (reverse coded) & 56 & 4.05 & 1.55 & 55 & 4.04 & 1.67 & 0.04 & -0.57 to 0.64 & 0.9 \\
\hline Outdoor toys & 56 & 4.23 & 1.43 & 55 & 4.47 & 1.09 & -0.09 & -0.57 to 0.39 & 0.7 \\
\hline \multicolumn{10}{|l|}{ PPAPP scale discourage } \\
\hline Promote screen time & 55 & 5.85 & 2.63 & 55 & 5.15 & 2.59 & 0.16 & -0.74 to 1.05 & 0.7 \\
\hline Promote inactivity & 56 & 4.41 & 1.88 & 54 & 5.00 & 2.36 & -0.22 & -0.94 to 0.50 & 0.5 \\
\hline Psychological control & 56 & 8.59 & 2.89 & 55 & 9.98 & 3.96 & -1.24 & -2.35 to -0.13 & 0.03 \\
\hline Restriction for safety concern & 56 & 13.00 & 5.37 & 55 & 12.87 & 5.36 & 0.18 & -1.67 to 2.04 & 0.8 \\
\hline
\end{tabular}

${ }^{a}$ Child active days per week adjusted differences are negative binomial regression model estimates adjusting for baseline outcome value, child gender, child age at baseline, and parent education. Parent active days per week, MVPA, and MVPA+walking incidence rate ratios are negative binomial regression model estimates adjusting for baseline outcome value, parent age at baseline, and parent education. All other secondary outcome adjusted differences are linear regression model estimates adjusting for baseline outcome value, parent age at baseline, and parent education.

MVPA, moderate-to-vigorous physical activity; PPAPP, Preschooler Physical Activity Parenting Practices.

those interventions. Although there is a significant focus on early intervention to prevent childhood obesity during critical windows of childhood development, it is not clear whether the optimal time to intervene is during the preschool period. Large epidemiological studies indicate that disparities in childhood obesity are present by the time children reach kindergarten. ${ }^{6}$ It may be that the optimal timing of childhood obesity prevention should begin earlier in life, and that developing a wide range of options to address treatment of childhood obesity at various stages will be an important component of a population-level strategy to reduce childhood obesity as it emerges. This study was not powered to detect the moderating effect of starting child BMI on intervention effectiveness, and although this study enrolled children who were at risk for obesity (BMI $\geq 50$ th percentile), children were eligible if they were normal weight, overweight, or already obese.
Future studies should consider whether personalized intervention content may be appropriate for childhood obesity prevention, treatment, or both. In addition, it is not clear whether the optimal strategy for childhood obesity prevention and treatment should be conducted in the clinical, community, or school settings. The current trial was implemented in participant's local built environment, suggesting that future interventions among low-income communities should be situated in some aspect of the built environment to facilitate ongoing physical activity. These findings also underscore the importance of supporting participants in applying strategies within their specific environmental contexts - and of understanding the particular structural barriers within them.

As a part of our exploratory analysis, we conducted a dose analysis that found that children who attended higher numbers of interventions sessions had lower BMI-Z at the 
7-month follow-up. This supports the hypothesis that increasing intervention dose receipt will lead to healthier BMI trajectories. However, further analysis indicated that participants who attended 11-15 in-person sessions did not have lower BMI-Z scores than participants who attended 6-10 inperson sessions. This suggests that meaningful BMI-Z reductions may be possible at lower doses of the intervention, which is especially important given the limited resources and availability of participants from low-income and minority populations. These dose-related findings should be interpreted with caution, as participants were not randomized to specific "doses" of the intervention, and participant characteristics may have confounded these conclusions.

This study has several limitations. First, because the study was conducted among Latino families, the findings should not be generalized to other populations. Second, the study was not adequately powered to detect small changes in secondary outcomes of child diet and physical activity. In addition, secondary outcomes were measured by parent report, and they were therefore subject to both social desirability and recall bias. This may have contributed to issues with reliability of the measures, which may partially explain why some of the changes in secondary outcomes did not persist at the 1-year follow-up. Third, because of the large number of statistical tests on secondary outcomes, there is an increased chance of at least one Type 1 error among these results. With these limitations in mind, and because the secondary outcomes did not show sustained changes, it would be important to evaluate the behavioral mechanism through which the intervention was effective, before drawing conclusions about scaling up the intervention for widespread uptake. Lastly, the study was not powered to assess differential effects based on baseline BMI category.

\section{Conclusions}

This personalized, family-centered behavioral intervention resulted in slower linear BMI growth over 1 year in low-income Latino children.

\section{Acknowledgments}

This study was funded by the Department of Pediatrics at Vanderbilt University Medical Center, Turner-Hazinski Award. In addition, Dr. Heerman's time was supported by a K23 award from NHLBI (K23 HL127104).

\section{Author Disclosure Statement}

No competing financial interests exist.

\section{References}

1. Hales CM, Carroll MD, Fryar CD, et al. Prevalence of obesity among adults and youth: United States, 2015-2016. NCHS Data Brief 2017:1-8.
2. Campbell MK. Biological, environmental, and social influences on childhood obesity. Pediatr Res 2016;79:205-211.

3. Singh GK, Kogan MD, Van Dyck PC, et al. Racial/ethnic, socioeconomic, and behavioral determinants of childhood and adolescent obesity in the United States: Analyzing independent and joint associations. Ann Epidemiol 2008;18:682-695.

4. Heerman WJ, Mitchell SJ, Thompson J, et al. Parental perception of built environment characteristics and built environment use among Latino families: A cross-sectional study. BMC Public Health 2016;16:1180.

5. Vargas CM, Stines EM, Granado HS. Health-equity issues related to childhood obesity: A scoping review. J Public Health Dent 2017;77(Suppl 1):S32-S42.

6. Min J, Wen X, Xue H, et al. Ethnic disparities in childhood BMI trajectories and obesity and potential causes among 29,250 US children: Findings from the Early Childhood Longitudinal StudyBirth and Kindergarten Cohorts. Int J Obes (Lond) 2018;42:16611670 .

7. Robert Wood Johnson Foundation. The state of obesity. 2018 Available at https://stateofobesity.org Last accessed April 23, 2019.

8. Bleich SN, Segal J, Wu Y, et al. Systematic review of communitybased childhood obesity prevention studies. Pediatrics 2013;132: e201-e210.

9. Janicke DM, Steele RG, Gayes LA, et al. Systematic review and meta-analysis of comprehensive behavioral family lifestyle interventions addressing pediatric obesity. J Pediatr Psychol 2014;39: 809-825.

10. Ash T, Agaronov A, Young T, et al. Family-based childhood obesity prevention interventions: A systematic review and quantitative content analysis. Int J Behav Nutr Phys Act 2017; 14:113.

11. Barkin SL, Heerman WJ, Sommer EC, et al. Effect of a behavioral intervention for underserved preschool-age children on change in body mass index: A randomized clinical trial. JAMA 2018;320: 450-460

12. French SA, Sherwood NE, Veblen-Mortenson S, et al. Multicomponent obesity prevention intervention in low-income preschoolers: Primary and subgroup analyses of the NET-Works randomized clinical trial, 2012-2017. Am J Public Health 2018; 108:1695-1706.

13. Branscum P, Sharma M. A systematic analysis of childhood obesity prevention interventions targeting Hispanic children: Lessons learned from the previous decade. Obes Rev 2011;12:e151-e158.

14. Teeters L, Singer-Gabella M, Jones S, et al. Operationalizing agency: A personalized approach to public health. Int J Commun Res Engage 2018;11:73-89.

15. Burgermaster M, Contento I, Koch $\mathrm{P}$, et al. Behavior change is not one size fits all: Psychosocial phenotypes of childhood obesity prevention intervention participants. Transl Behav Med 2018;8: 799-807.

16. Bandura A. Toward a psychology of human agency. Perspect Psychol Sci 2006;1:164-180.

17. Guskey TR. Closing achievement gaps: Revising Benjamin S Bloom's "Learning for Mastery". J Adv Acad 2007;19:8-31.

18. Heerman WJ, Burgess LE, Escarfuller J, et al. Competency Based Approach to Community Health $(\mathrm{COACH})$ : The methods of a family-centered, community-based, individually adaptive obesity randomized trial for pre-school child-parent pairs. Contemp Clin Trials 2018;73:1-7.

19. Heerman WJ, White RO, Barkin SL. Advancing informed consent for vulnerable populations. Pediatrics 2015;135:e562-e564. 
20. Heerman WJ, White RO, Hotop A, et al. A toolkit to enhance the informed consent process for community-engaged pediatric research. IRB 2016;38:8-14.

21. Kuczmarski RJ, Ogden CL, Guo SS, et al. 2000 CDC Growth Charts for the United States: Methods and development. Vital Health Stat 11 2002:1-190.

22. Hales CM, Fryar CD, Carroll MD, et al. Trends in obesity and severe obesity prevalence in US youth and adults by sex and age, 2007-2008 to 2015-2016. JAMA 2018;319:1723-1725.

23. White RO, Thompson JR, Rothman RL, et al. A health literate approach to the prevention of childhood overweight and obesity. Patient Educ Couns 2013;93:612-618.

24. Appel LJ, Clark JM, Yeh HC, et al. Comparative effectiveness of weight-loss interventions in clinical practice. N Engl J Med 2011; 365:1959-1968.

25. Po'e EK, Heerman WJ, Mistry RS, et al. Growing Right Onto Wellness (GROW): A family-centered, community-based obesity prevention randomized controlled trial for preschool child-parent pairs. Contemp Clin Trials 2013;36:436-449.

26. Mills SD, Malcarne VL, Fox RS, et al. Psychometric evaluation of the Brief Acculturation Scale for Hispanics. Hisp J Behav Sci 2014;36:164-174.

27. Ziegler P, Briefel R, Clusen N, et al. Feeding Infants and Toddlers Study (FITS): Development of the FITS survey in comparison to other dietary survey methods. J Am Diet Assoc 2006;106:S12-S27.

28. Heerman WJ, Jackson N, Hargreaves M, et al. Clusters of healthy and unhealthy eating behaviors are associated with body mass index among adults. $J$ Nutr Educ Behav 2017;49:415.e1-421.e1.

29. Centers for Disease Control and Prevention. Behavioral risk factor surveillance system. Available at www.cdc.gov/brfss/index.htm Last accessed March 10, 2010.

30. Wright JA, Adams WG, Laforge RG, et al. Assessing parental selfefficacy for obesity prevention related behaviors. Int J Behav Nutr Phys Act 2014;11:53.

31. O'Connor TM, Cerin E, Hughes SO, et al. Psychometrics of the preschooler physical activity parenting practices instrument among a Latino sample. Int J Behav Nutr Phys Act 2014;11:3.

32. Harold GT, Kerr DC, Van Ryzin M, et al. Depressive symptom trajectories among girls in the juvenile justice system: 24-month outcomes of an RCT of Multidimensional Treatment Foster Care. Prev Sci 2013;14:437-446.

33. Singer JD, Willett JB. Applied Longitudinal Data Analysis: Modeling Change and Event Occurrence. Oxford University Press: Oxford; New York, 2003.
34. Kahan BC, Morris TP. Assessing potential sources of clustering in individually randomised trials. BMC Med Res Methodol 2013;13: 58.

35. Wooldridge JM. Econometric Analysis of Cross Section and Panel Data, 2nd ed. MIT Press: Cambridge, MA, 2010.

36. Long JS, Freese J. Regression Models for Categorical Dependent Variables Using Stata, 3rd ed. Stata Press Publication, StataCorp LP: College Station, TX, 2014.

37. Cameron AC, Trivedi PK. Microeconometrics Using Stata. Stata Press: College Station, TX, 2010.

38. Heerman WJ, JaKa MM, Berge JM, et al. The dose of behavioral interventions to prevent and treat childhood obesity: A systematic review and meta-regression. Int J Behav Nutr Phys Act 2017;14: 157.

39. JaKa MM, Haapala JL, Trapl ES, et al. Reporting of treatment fidelity in behavioural paediatric obesity intervention trials: A systematic review. Obes Rev 2016;17:1287-1300.

40. Waters E, de Silva-Sanigorski A, Hall BJ, et al. Interventions for preventing obesity in children. Cochrane Database Syst Rev 2011; 12:CD001871.

41. Oude Luttikhuis $H$, Baur $L$, Jansen $H$, et al. Interventions for treating obesity in children. Cochrane Database Syst Rev 2009;1: CD001872.

42. Boon CS, Clydesdale FM. A review of childhood and adolescent obesity interventions. Crit Rev Food Sci Nutr 2005;45:511-525.

43. Young KM, Northern JJ, Lister KM, et al. A meta-analysis of family-behavioral weight-loss treatments for children. Clin Psychol Rev 2007;27:240-249.

44. Seo DC, Sa J. A meta-analysis of obesity interventions among U.S. minority children. J Adolesc Health 2010;46:309-323.

45. Stice E, Shaw H, Marti CN. A meta-analytic review of obesity prevention programs for children and adolescents: The skinny on interventions that work. Psychol Bull 2006;132:667-691.

Address correspondence to: William J. Heerman, MD, MPH Department of Pediatrics Vanderbilt University Medical Center 2146 Belcourt Avenue, 2nd Floor Nashville, TN 37209

E-mail: bill.heerman@vanderbilt.edu 
Appendix Table AI. Secondary Outcomes at 7 and 12 Months: Child Diet Items

7 Months

12 Months

\begin{tabular}{|c|c|c|c|c|c|c|}
\hline \multirow[b]{2}{*}{$\begin{array}{l}\text { Child } \\
\text { diet item }\end{array}$} & & \\
\hline & $\begin{array}{c}\text { Adjusted incidence } \\
\text { rate ratio }\end{array}$ & $95 \% \mathrm{Cl}$ & $p$ & $\begin{array}{c}\text { Adjusted incidence } \\
\text { rate ratio }\end{array}$ & $95 \% \mathrm{Cl}$ & $p$ \\
\hline Soda & 1.33 & $0.65-2.74$ & 0.4 & 1.29 & $0.80-2.09$ & 0.3 \\
\hline Juice & 0.91 & $0.56-1.50$ & 0.7 & 1.06 & $0.65-1.73$ & 0.8 \\
\hline Sweetened drinks & 1.11 & $0.55-2.22$ & 0.8 & 1.02 & $0.63-1.64$ & 0.9 \\
\hline Fruit & 1.35 & $|.07-| .7 \mid$ & 0.01 & 1.23 & $0.96-1.57$ & 0.1 \\
\hline Vegetables & 1.07 & $0.68-1.69$ & 0.8 & 0.76 & $0.42-1.37$ & 0.4 \\
\hline Sweets & 0.91 & $0.57-1.46$ & 0.7 & 0.73 & $0.51-1.04$ & 0.08 \\
\hline Snacks & 1.62 & $1.13-2.32$ & 0.008 & 0.71 & $0.47-1.08$ & 0.1 \\
\hline Other dairy & 0.96 & $0.70-1.32$ & 0.8 & 0.79 & $0.55-1.14$ & 0.2 \\
\hline Water & 1.03 & $0.84-1.26$ & 0.8 & 0.87 & $0.69-1.10$ & 0.3 \\
\hline
\end{tabular}

Analytic sample was 106 at 7 months and 104 at 12 months for all outcomes, except for sweets (7-month $n=94$, 12-month $n=92)$ due to additional missing data at baseline. Adjusted incidence rate ratios are Poisson regression model estimates adjusting for baseline value of the outcome variable, child gender, child age at baseline, and parent education.

$95 \% \mathrm{Cl}, 95 \%$ confidence interval.

\section{Appendix Table A2. Secondary Outcomes at 7 and 12 Months: Child and Parent Other Health Outcomes}

\begin{tabular}{|c|c|c|c|c|c|c|}
\hline \multirow[b]{2}{*}{ Secondary outcome } & \multicolumn{3}{|c|}{7 Months } & \multicolumn{3}{|c|}{12 Months } \\
\hline & $\begin{array}{l}\text { Adjusted difference } \\
\text { or incidence } \\
\text { rate ratio }\end{array}$ & $95 \% \mathrm{Cl}$ & $p$ & $\begin{array}{l}\text { Adjusted difference } \\
\text { or incidence } \\
\text { rate ratio }\end{array}$ & $95 \% \mathrm{Cl}$ & $p$ \\
\hline Child active days per week & 0.66 & 0.37 to 1.16 & 0.1 & 0.70 & 0.49 to 1.01 & 0.06 \\
\hline Parent BMI $\left(\mathrm{kg} / \mathrm{m}^{2}\right)$ & -0.31 & -0.82 to 0.20 & 0.2 & -0.48 & -1.15 to 0.18 & 0.2 \\
\hline Parent diet practices & 0.07 & -1.23 to 1.36 & 0.9 & -0.29 & -1.67 to 1.08 & 0.7 \\
\hline Parent active days per week & 0.91 & 0.52 to 1.57 & 0.7 & 0.99 & 0.68 to 1.43 & 0.9 \\
\hline Parent MVPA per week (minutes) & 0.59 & 0.29 to 1.18 & 0.1 & 1.45 & 0.79 to 2.69 & 0.2 \\
\hline Parent MVPA+walking per week (minutes) & 0.82 & 0.51 to 1.32 & 0.4 & 1.53 & 0.97 to 2.39 & 0.06 \\
\hline \multicolumn{7}{|l|}{ Parent self-efficacy for child health behaviors } \\
\hline Avoid sugary drinks & 0.71 & -0.61 to 2.03 & 0.3 & -0.40 & -1.81 to 1.02 & 0.6 \\
\hline Avoid fruit juice & 0.95 & -0.44 to 2.34 & 0.2 & 0.62 & -0.83 to 2.07 & 0.4 \\
\hline Encourage physical activity & -0.42 & -1.58 to 0.75 & 0.5 & 0.14 & -0.99 to 1.27 & 0.8 \\
\hline Encourage fruits and vegetables & 0.30 & -0.97 to 1.57 & 0.6 & 0.96 & -0.29 to 2.22 & 0.1 \\
\hline \multicolumn{7}{|l|}{ PPAPP scale encourage } \\
\hline Engagement & 1.88 & -2.71 to 6.46 & 0.4 & 2.29 & -1.93 to 6.52 & 0.3 \\
\hline Lack money for sports (reverse coded) & -0.30 & -0.87 to 0.26 & 0.3 & -0.02 & -0.56 to 0.52 & 0.9 \\
\hline Outdoor toys & -0.07 & -0.52 to 0.39 & 0.8 & -0.02 & -0.48 to 0.43 & 0.9 \\
\hline \multicolumn{7}{|l|}{ PPAPP scale discourage } \\
\hline Promote screen time & -0.63 & $-|.5|$ to 0.25 & 0.2 & -0.45 & -1.39 to 0.49 & 0.3 \\
\hline Promote inactivity & -0.15 & -0.86 to 0.56 & 0.7 & -0.20 & -0.83 to 0.43 & 0.5 \\
\hline Psychological control & -0.51 & -1.68 to 0.66 & 0.4 & -0.33 & -1.52 to 0.87 & 0.6 \\
\hline Restriction for safety concern & -0.08 & -1.93 to 1.77 & 0.9 & -0.03 & -1.74 to 1.69 & $>0.9$ \\
\hline
\end{tabular}

${ }^{a}$ Child active days per week adjusted differences are negative binomial regression model estimates adjusting for baseline outcome value, child gender, child age at baseline, and parent education. Parent active days per week, MVPA, and MVPA+walking incidence rate ratios are negative binomial regression model estimates adjusting for baseline outcome value, parent age at baseline, and parent education. All other secondary outcome adjusted differences are linear regression model estimates adjusting for baseline outcome value, parent age at baseline, and parent education.

MVPA, moderate-to-vigorous physical activity; PPAPP, Preschooler Physical Activity Parenting Practices. 


\begin{tabular}{|c|c|c|c|c|c|c|c|c|}
\hline $\begin{array}{l}\text { Dose } \\
\text { delivered }\end{array}$ & $\begin{array}{l}\text { Frequency: } \\
\text { face-to-face } \\
\text { (intensive) }\end{array}$ & $\%$ & $\begin{array}{l}\text { Frequency: } \\
\text { phone make-up } \\
\text { (intensive) }\end{array}$ & $\%$ & $\begin{array}{c}\text { Frequency: } \\
\text { total } \\
\text { (intensive) }\end{array}$ & $\%$ & $\begin{array}{c}\text { Frequency: } \\
\text { phone calls } \\
\text { (maintenance) }\end{array}$ & $\%$ \\
\hline 0 & 9 & 15.3 & 5 & 8.5 & 4 & 6.8 & 16 & 27.1 \\
\hline I & 8 & 13.6 & 9 & 15.3 & 4 & 6.8 & 3 & 5.1 \\
\hline 2 & 4 & 6.8 & 2 & 3.4 & 1 & 1.7 & 2 & 3.4 \\
\hline 3 & 2 & 3.4 & 7 & 11.9 & 0 & 0 & 3 & 5.1 \\
\hline 4 & I & 1.7 & 5 & 8.5 & 2 & 3.4 & 3 & 5.1 \\
\hline 5 & 3 & 5.1 & 13 & 22 & 2 & 3.4 & 8 & 13.6 \\
\hline 6 & 1 & 1.7 & 5 & 8.5 & 0 & 0 & 24 & 40.7 \\
\hline 7 & 1 & 1.7 & 3 & 5.1 & 1 & 1.7 & - & - \\
\hline 8 & 3 & 5.1 & 4 & 6.8 & 1 & 1.7 & - & - \\
\hline 9 & 2 & 3.4 & 2 & 3.4 & 6 & 10.2 & - & - \\
\hline 10 & 11 & 18.6 & 1 & 1.7 & 0 & 0 & - & - \\
\hline 11 & 3 & 5.1 & 1 & 1.7 & I & 1.7 & - & - \\
\hline 12 & 6 & 10.2 & 0 & 0 & 3 & 5.1 & - & - \\
\hline 13 & 1 & 1.7 & 1 & 1.7 & 0 & 0 & - & - \\
\hline 14 & 3 & 5.1 & 1 & 1.7 & 1 & 1.7 & - & - \\
\hline 15 & I & 1.7 & 0 & 0 & 33 & 55.9 & - & - \\
\hline
\end{tabular}

Intervention group $n=59$.

\begin{tabular}{|c|c|c|c|c|c|c|c|c|c|}
\hline & \multicolumn{3}{|c|}{$\begin{array}{l}\text { 4-Month child } \\
\text { BMI-Z }(n=1 / 2)\end{array}$} & \multicolumn{3}{|c|}{$\begin{array}{l}\text { 7-Month child } \\
\text { BMI-Z }(n=107)\end{array}$} & \multicolumn{3}{|c|}{$\begin{array}{l}\text { I2-Month } \\
\text { child BMI-Z }(n=106)\end{array}$} \\
\hline & $\begin{array}{l}\text { Adjusted } \\
\text { estimate }\end{array}$ & $95 \% \mathrm{Cl}$ & $p$ & $\begin{array}{l}\text { Adjusted } \\
\text { estimate }\end{array}$ & $95 \% \mathrm{Cl}$ & $p$ & $\begin{array}{l}\text { Adjusted } \\
\text { estimate }\end{array}$ & $95 \% \mathrm{Cl}$ & $p$ \\
\hline \multicolumn{10}{|c|}{$\begin{array}{l}\text { Model I: face-to-face intensive } \\
\text { modality }\end{array}$} \\
\hline Face-to-face dose & -0.004 & -0.017 to 0.009 & 0.5 & -0.017 & -0.032 to -0.003 & 0.02 & -0.007 & -0.024 to 0.010 & 0.4 \\
\hline \multicolumn{10}{|l|}{$\begin{array}{l}\text { Model 2: maintenance phone } \\
\text { call modality }\end{array}$} \\
\hline Maintenance dose & -0.012 & -0.036 to 0.012 & 0.3 & -0.036 & -0.063 to -0.009 & 0.01 & -0.018 & -0.050 to 0.014 & 0.3 \\
\hline \multicolumn{10}{|c|}{$\begin{array}{l}\text { Model 3: modality main effects } \\
\text { and interaction }\end{array}$} \\
\hline Face-to-face dose & 0.015 & -0.043 to 0.072 & 0.6 & 0.010 & -0.055 to 0.075 & 0.8 & -0.003 & -0.078 to 0.072 & 0.9 \\
\hline Maintenance dose & -0.023 & -0.085 to 0.039 & 0.5 & -0.033 & -0.104 to 0.038 & 0.4 & -0.040 & -0.123 to 0.042 & 0.3 \\
\hline $\begin{array}{l}\text { Interaction: face-to-face } \\
\text { by maintenance }\end{array}$ & -0.001 & -0.013 to 0.010 & 0.8 & -0.002 & -0.015 to 0.011 & 0.8 & 0.003 & -0.012 to 0.018 & 0.7 \\
\hline
\end{tabular}

Estimates are from regression models adjusting for baseline value of the outcome variable, child gender, and child age at baseline. Control group has 0 for both dose modalities. 